\title{
Development of a SPECT Tracer to Image c-Met Expression in a Xenograft Model of Non-Small Cell Lung Cancer
}

\author{
Zhaoguo Han*1,2, Yadi Xiao*1,2, Kai Wang ${ }^{1,2}$, Ji Yan ${ }^{1,2}$, Zunyu Xiao ${ }^{1,2}$, Fang Fang ${ }^{1,2}$, Zhongnan Jin ${ }^{1,2}$, Yang Liu ${ }^{1,2}$, \\ Xilin Sun ${ }^{1-3}$, and Baozhong Shen ${ }^{1,2}$ \\ ${ }^{I}$ Molecular Imaging Research Center, Harbin Medical University, Harbin, Heilongjiang, China; ${ }^{2}$ TOF-PET/CT/MR Center, Fourth \\ Hospital of Harbin Medical University, Harbin, Heilongjiang, China; and ${ }^{3}$ Molecular Imaging Program at Stanford, Department of \\ Radiology, Stanford University School of Medicine, Stanford, California
}

\begin{abstract}
Elevated expression of the c-Met receptor plays a crucial role in cancers. In non-small cell lung cancer (NSCLC), aberrant activation of the c-Met signaling pathway contributes to tumorigenesis and cancer progression and may mediate acquired resistance to epidermal growth factor receptor-targeted therapy. c-Met is therefore emerging as a promising therapeutic target for NSCLC, and methods for noninvasive in vivo assessment of c-Met expression would improve NSCLC treatment and diagnosis. Methods: We developed a new c-Met-binding peptide (cMBP) radiotracer, ${ }^{99 m T c-h y d r a z i n e ~}$ nicotinamide (HYNIC)-CMBP, for SPECT imaging. Cell uptake assays were performed on 2 NSCLC cell lines with different c-Met expressions: H1993 (high expression) and H1299 (no expression). In vivo tumor specificity was assessed by SPECT imaging in tumorbearing mice at $0.5,1,2$, and $4 \mathrm{~h}$ after injection of the probe. Blocking assays, biodistribution, and autoradiography were also conducted to determine probe specificity. Results: ${ }^{99 m T c-H Y N I C-c M B P}$ was prepared with high efficiency and showed higher uptake in H1993 cells than in $\mathrm{H} 1299$ cells. Biodistribution and autoradiography also showed significantly higher percentages of the injected dose for ${ }^{99 \mathrm{mTC}-\mathrm{HYNIC}-}$ cMBP in $\mathrm{H} 1993$ tumors than in $\mathrm{H} 1299$ tumors at $0.5 \mathrm{~h}(4.74 \pm 1.43 \% / \mathrm{g}$ and $1.00 \pm 0.37 \% / \mathrm{g}$, respectively; $P<0.05$ ). $\mathrm{H} 1993$ tumors were clearly visualized at $0.5 \mathrm{~h}$ in SPECT images, whereas $\mathrm{H} 1299$ tumors were not observed at any time. The specificity of ${ }^{99 m T c-H Y N I C-c M B P}$ for c-Met was demonstrated by a competitive block with an excess of nonradiolabeled peptide. Conclusion: For c-Met-targeted SPECT imaging of NSCLC, we developed ${ }^{99 m}$ TC-HYNIC-cMBP, a tracer that specifically binds to c-Met with favorable pharmacokinetics in vitro and in vivo.
\end{abstract}

Key Words: c-Met; targeted peptide; NSCLC; SPECT

J Nucl Med 2018; 59:1686-1691

DOI: 10.2967/jnumed.117.206730

$\mathbf{T}$ he c-Met receptor is a tyrosine kinase receptor encoded by a protooncogene (1). On binding of hepatocyte growth factor, active

Received Dec. 6, 2017; revision accepted May 8, 2018.

For correspondence or reprints contact either of the following: Xilin Sun, Molecular Imaging Research Center, Harbin Medical University, 766 Xiangan

N St., Songbei District, Harbin, Heilongjiang, China, 150028.

E-mail: sunx|@ems.hrbmu.edu.cn

Baozhong Shen, Molecular Imaging Research Center, Harbin Medical University, 766 Xiangan N. St., Songbei District, Harbin, Heilongjiang, China, 150028.

E-mail: shenbz@ems.hrbmu.edu.cn

${ }^{*}$ Contributed equally to this work.

Published online May 18, 2018.

COPYRIGHT (C 2018 by the Society of Nuclear Medicine and Molecular Imaging.
c-Met stimulates various signaling pathways implicated in cellular processes, including cell proliferation, motility, and apoptosis (2). Aberrantly high expression of c-Met resulting from gene amplification and protein overexpression increases c-Met activation and oncogenic transformation (3). Elevated c-Met expression has been observed in many types of cancer, including thyroid, pancreatic, and lung (4).

Lung cancer has the highest incidence and mortality rates worldwide (5), and non-small cell lung cancer (NSCLC) accounts for about $80 \%$ of lung cancer cases (6). High expression of c-Met has been detected in many cases of NSCLC and is thought to play an important role in promoting tumorigenesis and cancer progression (7). Activation of hepatocyte growth factor/c-Met downstream signaling by the phosphatidylinositol 3 kinase/protein kinase $\mathrm{B}$ and mitogen-activated protein kinase pathways can promote tumor growth, metastasis, angiogenesis, and apoptosis inhibition, which contribute to invasiveness and poor prognosis in NSCLC. Furthermore, c-Met gene amplification is a significant mechanism mediating resistance to therapies targeting the epidermal growth factor receptor in NSCLC $(8,9)$.

Studies suggest that c-Met is an effective drug target for treating NSCLC (10), and combination therapies targeting c-Met and the epidermal growth factor receptor have attracted attention in the clinical setting (11). However, limitations in early detection challenge the overall efficacy of cancer treatment. Typically, the methods of screening for lung cancer, such as CT, detect tumors mostly at middle or advanced stages (12). Diagnoses for lung cancer currently rely on biopsies, with multiple disadvantages such as a risk of pleural metastasis, patient intolerance, and sampling inaccuracy due to tumor heterogeneity (13). It is therefore desirable to develop more precise and less invasive methods to diagnose lung cancer, particularly at early stages.

Molecular imaging is a noninvasive method to obtain qualitative and quantitative information on tumor-associated molecular targets in vivo. Over decades, c-Met has increasingly been used as a biomarker for molecular imaging. Despite significant advances in c-Met-targeted imaging, problems remain. For instance, an anti-c-Met monoclonal antibody, DN30 $(\sim 150 \mathrm{kDa})$, labeled with ${ }^{89} \mathrm{Zr}$ provided quantitative images with high uptake in gastric cancer. However, the tracer had prolonged circulation and slow clearance, reducing tumor-to-background contrast and leading to late optimal imaging times (3-5 d) (14). An anti-c-Met diabody ( $~ 55 \mathrm{kDa}$ ) labeled with ${ }^{89} \mathrm{Zr}$ achieved acceptable images but also showed slow clearance (15). These examples highlight the disadvantages of antibodybased tracers: long biologic half-life and slow clearance.

More recent imaging strategies using peptide targeting have received greater attention by overcoming most of the limitations 
of antibody-based tracers. Indeed, peptide-based tracers have a smaller size, simpler synthesis, faster clearance, and lower risk of immunogenicity (16). GE-137 ( 4.2 kDa), a c-Met-targeted peptide labeled with cyanine dye, produced encouraging results in detecting malignant polyps in high-risk colon cancer patients by optical imaging (17). Based on same targeted peptide to GE-137, ${ }^{18} \mathrm{~F}$-AH113804 also successfully assessed locoregional recurrence of breast cancer (18).

${ }^{99 \mathrm{~m}} \mathrm{Tc}$ is widely used in nuclear medicine. To our knowledge, ${ }^{99 \mathrm{~m}} \mathrm{Tc}-$ labeled peptides targeting c-Met have not been studied in NSCLC. A c-Met-binding peptide (cMBP) (peptide KSLSRHDHIHHH) identified through phage display screening was previously labeled with a fluorescent dye to detect c-Met in U87MG glioblastoma $(19,20)$. Here, cMBP was modified with a bifunctional chelator, hydrazine nicotinamide (HYNIC), for labeling with ${ }^{99 \mathrm{~m} T \mathrm{Tc}}$ (half-life, $6.02 \mathrm{~h}$ ) ( ${ }^{99 m}$ Tc-HYNIC-cMBP) and used to assess c-Met expression in NSCLC by SPECT.

\section{MATERIALS AND METHODS}

\section{Radiosynthesis of ${ }^{99 m}$ Tc-HYNIC-cMBP}

ChinaPeptides Co., Ltd., synthesized HYNIC-cMBP, which was radiolabeled with ${ }^{99 \mathrm{~m}} \mathrm{Tc}$ as previously described (21). Briefly, $5 \mu \mathrm{g}$ of HYNIC-cMBP were added to ethylenediamine- $N, N^{\prime}$-diacetic acid $(10 \mathrm{mg}) /$ tricine $(20 \mathrm{mg})$ in $1 \mathrm{~mL}$ of phosphate-buffered saline (PBS, $\mathrm{pH}$ 6-7), followed by $0.5 \mathrm{~mL}$ of ${ }^{99} \mathrm{mcO}_{4}$ solution ( $370 \mathrm{MBq}$ ) and $20 \mu \mathrm{L}$ of tin-II solution $\left(10 \mathrm{mg}\right.$ of $\mathrm{SnCl}_{2}$ in $10 \mathrm{~mL}$ of $\left.0.1 \mathrm{~N} \mathrm{HCl}\right)$. All reagents were purchased from Sigma. The mixture was heated $\left(85^{\circ} \mathrm{C}, 15 \mathrm{~min}\right.$, nitrogen protection) and then cooled to room temperature. The reaction mixture was purified with a Sep-Pak C18 Plus cartridge (Waters), and the radiolabeled peptide was collected.

The partition coefficient of ${ }^{99 \mathrm{~m}} \mathrm{Tc}$-HYNIC-cMBP was measured in an octanol and saline system. A 7.4 MBq activity of ${ }^{99 \mathrm{~m}} \mathrm{Tc}-\mathrm{HYNIC}-\mathrm{cMBP}$ was mixed with the octanol $(0.5 \mathrm{~mL})$ and saline $(0.5 \mathrm{~mL})$ system for $1 \mathrm{~h}$. Then, the mixture was centrifuged $(3,000 \mathrm{rpm}, 5 \mathrm{~min})$, and activity from each layer (samples of $100 \mu \mathrm{L}$ ) was counted using a $\gamma$-counter (PerkinElmer 2480).

\section{Cell Culture}

Two NSCLC cell lines were selected-H1993 (high c-Met expression) and H1299 (no c-Met expression) —and cultured as previously reported (22).

\section{Determination of Dissociation Constant $\left(\mathbf{K}_{\mathrm{d}}\right)$}

H1993 cells with high c-Met expression were used in a saturation binding experiment to determine the $K_{d}$ of ${ }^{99 \mathrm{~m} T c-H Y N I C-c M B P}$ (23). Briefly, H1993 cells were seeded in two 24 -well plates at $0.2 \times 10^{6}$ cells per well $24 \mathrm{~h}$ beforehand. A stock solution of ${ }^{99 \mathrm{~m}} \mathrm{Tc}-\mathrm{HYNIC}-\mathrm{cMBP}$ was diluted with medium to 6 concentrations $(1,10,40,80,100$, and 160 $\mathrm{nM}$ ). Increasing concentrations of tracer were added to the wells of one plate to assess cell-bound activity, and nonspecific binding was determined in the other plate by adding nonradiolabeled cMBP $(100 \mu \mathrm{M})$. After incubation for $0.5 \mathrm{~h}$ at $4^{\circ} \mathrm{C}$, the tracer was removed. The cells were washed with cold PBS, and activity was measured. Specific binding was calculated by subtracting nonspecific binding from cell-bound activity. $K_{d}$ was determined from specific binding curves by using nonlinear regression curve fits (GraphPad Prism software, version 5).

\section{Cellular Uptake and Internalization}

${ }^{99 m}$ Tc-HYNIC-cMBP cellular uptake and blocking with nonradiolabeled cMBP were performed at 15, 30, 60, 120, and $240 \mathrm{~min}$ as previously reported (22).

c-Met-positive H1993 cells were used to evaluate whether ${ }^{99 \mathrm{~m} T c-}$ HYNIC-cMBP was internalized (24). Briefly, H1993 cells were seeded in 12 -well plates $\left(5 \times 10^{5}\right.$ cells $)$. After $24 \mathrm{~h},{ }^{99 \mathrm{~m} T \mathrm{Tc}-H Y N I C-}$ cMBP was added $(37 \mathrm{kBq} / \mathrm{mL})$ and incubated for different times. Free ${ }^{99 \mathrm{~m}} \mathrm{Tc}-\mathrm{HYNIC}-\mathrm{cMBP}$ was removed, and the cells were washed with ice-cold PBS followed by $0.2 \mathrm{M}$ glycine buffer in $4 \mathrm{M}$ urea ( $\mathrm{pH} 2.5$ ) for $5 \mathrm{~min}$ on ice to determine membrane-bound activity. Next, the cells were harvested using $1 \mathrm{~N} \mathrm{NaOH}$ to determine internalized activity. The results are presented as the internalized percentage of cellassociated activity (membrane-bound + internalized).

\section{Animal Xenograft Models}

Female BALB/c nude mice (5-6 wk old, weighing 19-23 g) were implanted subcutaneously with $\mathrm{H} 1993$ or H1299 $\left(5 \times 10^{6}\right.$ cells) in the right shoulder. Tumor volume was measured by calipers until reaching about $500 \mathrm{~mm}^{3}(\sim 5-6 \mathrm{wk})$. All animal experiments were approved by the Harbin Medical University Animal Ethics Committee in accordance with Chinese legislation and followed relevant guidelines. The institutional review board approved this study on mice with NSCLC tumor xenografts.

\section{In Vitro and In Vivo Stability}

The radiochemical purity of ${ }^{99 \mathrm{~m} T c-H Y N I C-c M B P}$ incubated in either mouse serum or PBS at $37^{\circ} \mathrm{C}$ was measured for $0,0.5,1,2$, and $4 \mathrm{~h} .{ }^{99 \mathrm{~m}} \mathrm{Tc}-\mathrm{HYNIC}-\mathrm{cMBP}$ was collected and diluted with PBS at baseline to $0.37 \mathrm{MBq}$ in $0.5 \mathrm{~mL}$ of solution A (99.9:0.1 water:trifluoroacetic acid), and radiochemical purity was measured by radio-high-performance liquid chromatography (HPLC). At subsequent time points, the probe samples were added to $0.5 \mathrm{~mL}$ of dimethyl formamide to precipitate protein. After centrifugation, the supernatant was diluted with $0.5 \mathrm{~mL}$ of solution A and analyzed with HPLC.

In vivo stability was determined with a procedure described previously (25). Briefly, H1993 tumor-bearing mice were injected with ${ }^{99 \mathrm{~m} T c-H Y N I C-c M B P}(11.1 \mathrm{MBq}$ in $150 \mu \mathrm{L}$ of saline) and euthanized $1 \mathrm{~h}$ afterward. Blood and urine were collected and immediately centrifuged to remove blood cells. Plasma and urine were added to $0.5 \mathrm{~mL}$ of $1 \%$ Triton X-100 (Sigma) in dimethyl formamide for further centrifugation. Then, supernatant portions of each sample were diluted with $0.5 \mathrm{~mL}$ of solution A for radio-HPLC analysis. Tumors and liver were homogenized with $0.5 \mathrm{~mL}$ of $1 \%$ Triton X-100 in dimethyl formamide and then centrifuged. The supernatants were diluted with $0.5 \mathrm{~mL}$ of solution A for radio-HPLC analysis. RadioHPLC (GX-281; Gilson) used a C18 column $(10 \mu \mathrm{m}, 19 \times 250 \mathrm{~mm}$; Waters) with a mobile phase of $50 \%$ ethanol at a flow rate of $5 \mathrm{~mL} / \mathrm{min}$. The eluted fractions were collected for $30 \mathrm{~s} /$ tube to measure radioactivity, and the resultant radio-HPLC chromatogram was plotted.

\section{In Vivo SPECT Imaging}

SPECT scanning of tumor-bearing mice (injected with $8.51 \mathrm{MBq}$ of $99 \mathrm{~m}$ Tc-HYNIC-cMBP) was performed with a clinical SPECT scanner (Discovery 670H3100NA; GE Healthcare), equipped with low-energy, high-resolution collimators with parallel pinholes. All images were obtained through detector 1 for anterior static scanning (100 counts), with a zoom factor of 1.00 , and stored at a resolution of $1,024 \times 1,024$. The energy window setting was $140 \mathrm{keV}$. Image analysis was performed with a Xeleris functional imaging workstation (version 3.1; GE Healthcare). The ratio of counts in the tumor to counts in the contralateral tissue (T/C) was calculated over the regions of interest.

\section{Biodistribution and Pharmacokinetics}

The tumor-bearing mice were injected with $1.85 \mathrm{MBq}$ of ${ }^{99 \mathrm{~m}} \mathrm{Tc}-$ HYNIC-cMBP and euthanized at serial points for biodistribution testing (22).

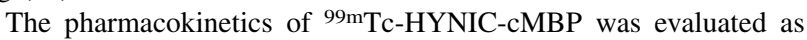
previously described (26), with modifications. The mice were 


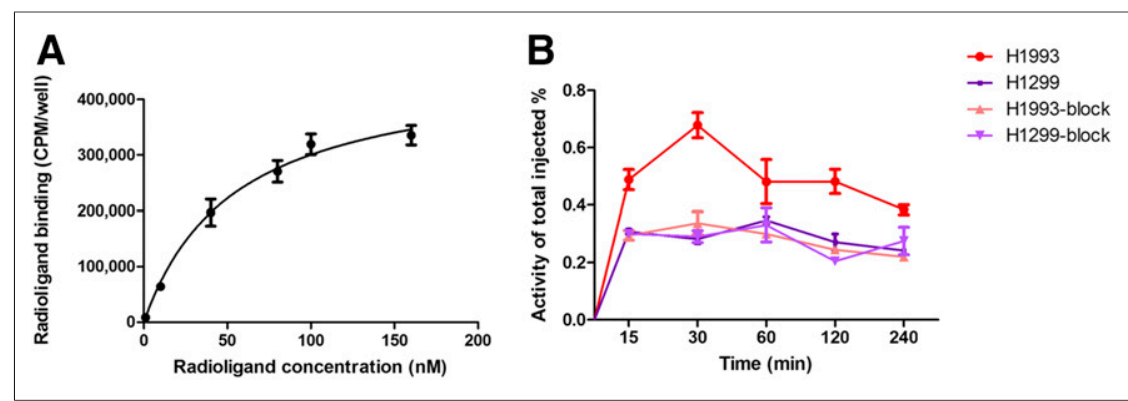
$56.30 \pm 2.11$. (B) Cell uptake and block-uptake of ${ }^{99 m T c-H Y N I C-c M B P}$ in NSCLC cells. CPM $=$ counts/min.
FIGURE 1. (A) Saturation curve for binding of $99 \mathrm{mTC}-\mathrm{HYNIC}-\mathrm{cMBP}$ to $\mathrm{H} 1993$ cells with $K_{d}$ of

photoreceptive film for $24 \mathrm{~h}$ and then imaged with a Cyclone Plus storage phosphor system (PerkinElmer).

\section{Western Blots}

and Immunofluorescence

Western blots and immunofluorescence experiments were performed as previously reported (22). The concentration of anti-cMet primary antibody (Abcam-ab51067) was 1:1,000 for Western blots and 1:100 for immunofluorescence.

\section{Statistical Analysis}

All data are expressed as mean $\pm \mathrm{SD}(n=3)$. Statistical analyses were performed using euthanized, and blood $(100 \mu \mathrm{L})$ was drawn by cardiac puncture at 3,9 , $15,30,45,60$, and 120 min after injection and centrifuged to collect the plasma. The plasma (extracted at $30 \mathrm{~min}$ ) was mixed with $10 \%$ sulfosalicylic acid to precipitate protein. The activity of the protein precipitate and supernatant was measured, and a time-logarithmicversus-plasma activity curve was plotted. Tracer elimination followed first-order reaction kinetics, and the elimination rate constant was calculated as the negative slope of the linear part of the plotted curve. The elimination half-life was calculated as $\ln (2) /$ elimination rate constant.

\section{Blocking Assays}

For blocking assays in SPECT imaging and biodistribution, nonradiolabeled cMBP was preinjected into $\mathrm{H} 1993$ xenografts at $100 \mathrm{mg}$ / $\mathrm{kg}$ of body weight $1 \mathrm{~h}$ before injection of the ${ }^{99 \mathrm{~m}} \mathrm{Tc}-\mathrm{HYNIC}-\mathrm{cMBP}$.

\section{Autoradiography}

Tumor-bearing mice were euthanized at $0.5 \mathrm{~h}$ after injection. Tumors were excised, embedded within optimal-cutting-temperature compound, and frozen at $-80^{\circ} \mathrm{C}$. Autoradiography, hematoxylin and eosin staining, and immunofluorescence staining were performed on consecutive tumor sections $(10 \mu \mathrm{m})$. Sections were exposed to
Prism software. Statistical differences between the groups were estimated using the $t$ test. A $P$ value of less than 0.05 was considered statistically significant.

\section{RESULTS}

\section{Radiosynthesis and Characterization of ${ }^{99 \mathrm{~m} T c-H Y N I C-c M B P}$}

The process of radiochemical synthesis and specific binding to c-Met of ${ }^{99 m}$ Tc-HYNIC-cMBP is illustrated in Supplemental Figures 1A and 1B (supplemental materials are available at http:// jnm.snmjournals.org). The product was obtained with a yield of at least $75 \%$ and a radiochemical purity of more than $98 \%$ after purification. The $\log \mathrm{P}$ value was $-3.003 \pm 0.48$, indicating that the probe was water-soluble.

\section{Determination of $\mathbf{K}_{\mathbf{d}}$}

The binding affinity of $99 \mathrm{~m}$ Tc-HYNIC-cMBP to H1993 cells was determined by its specific binding curve (Fig. 1A) to have a $K_{d}$ of $56.30 \pm 2.11$. According to a reported theory, the $K_{d}$ value of ${ }^{99 m}$ Tc-HYNIC-cMBP exhibits moderate affinity $(1 \mathrm{nM}-1 \mu \mathrm{M})$ (27), suggesting that ${ }^{99 \mathrm{~m}} \mathrm{Tc}-\mathrm{HYNIC}$-cMBP would be effective as a tumor c-Met radiotracer.

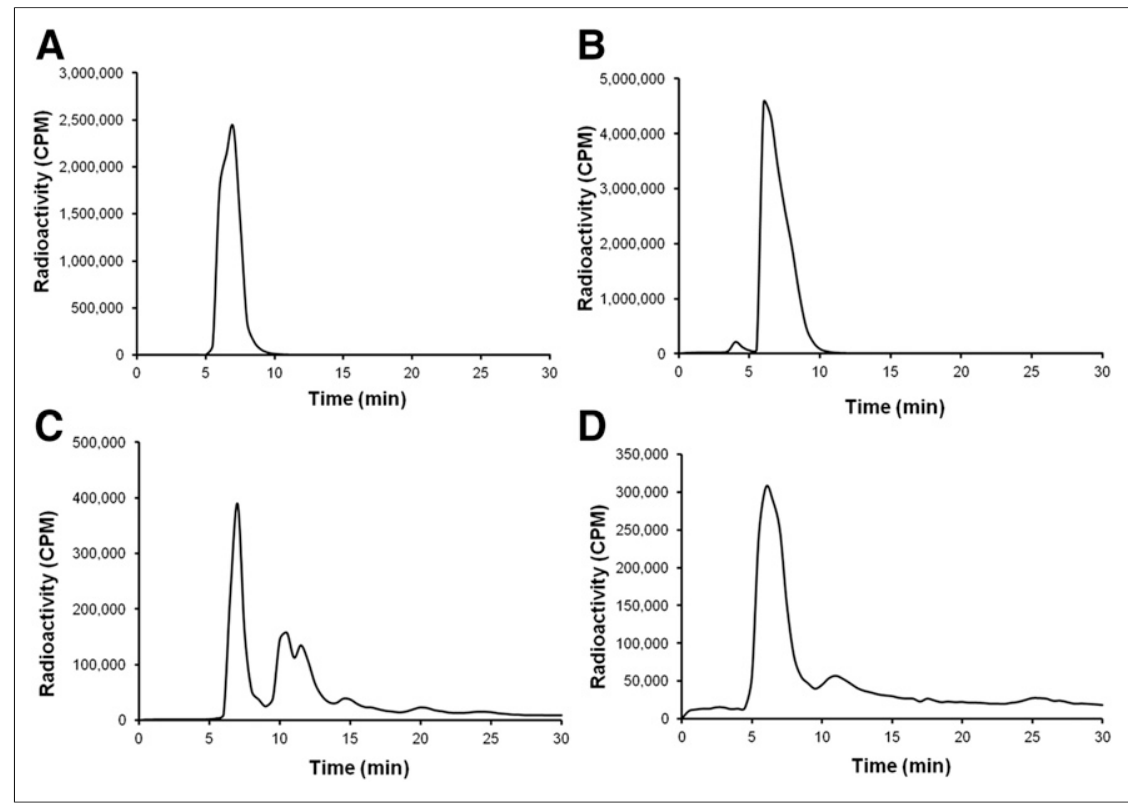

FIGURE 2. In vivo stability of ${ }^{99 m} \mathrm{Tc}-\mathrm{HYNIC}-\mathrm{cMBP}$ as indicated by radiochemical purity in samples of plasma (A), tumor $(B)$, liver $(C)$, and urine $(D)$ at $1 \mathrm{~h}$. CPM $=$ counts $/ \mathrm{min}$.

\section{Cellular Uptake and Blocking Assays}

Cellular uptake and blocking assays for H1993 and H1299 cells are shown in Figure 1B. There was rapid uptake of ${ }^{99 \mathrm{~m}} \mathrm{Tc}-$ HYNIC-cMBP, which peaked at $30 \mathrm{~min}$ in $\mathrm{H} 1993$ cells. The tracer subsequently decreased gradually at 60,120 , and $240 \mathrm{~min}$. In contrast, visibly lower cellular uptake was noted in the H1299 cells, with no obvious uptake trend. The accumulation of ${ }^{99 m}$ Tc-HYNIC-cMBP in H1993 cells reached its highest level $(0.68 \% \pm 0.06 \%$ of total input activity) at $30 \mathrm{~min}$, about 2.4fold higher than in $\mathrm{H} 1299$ cells $(P<0.01)$. In blocking assays with an excess of nonradiolabeled cMBP, uptake of ${ }^{99 \mathrm{~m}} \mathrm{Tc}-$ HYNIC-cMBP in $\mathrm{H} 1993$ cells at $30 \mathrm{~min}$ was lower $(0.33 \% \pm 0.06 \%, P<0.01)$, and uptake in H1299 cells remained unchanged. These results suggest that ${ }^{99 m}$ Tc-HYNIC-cMBP binds specifically to the c-Met expressed in H1993 cells.

Internalization results (Supplemental Fig. 2) indicated that ${ }^{99 \mathrm{~m}}$ Tc-HYNIC-cMBP 


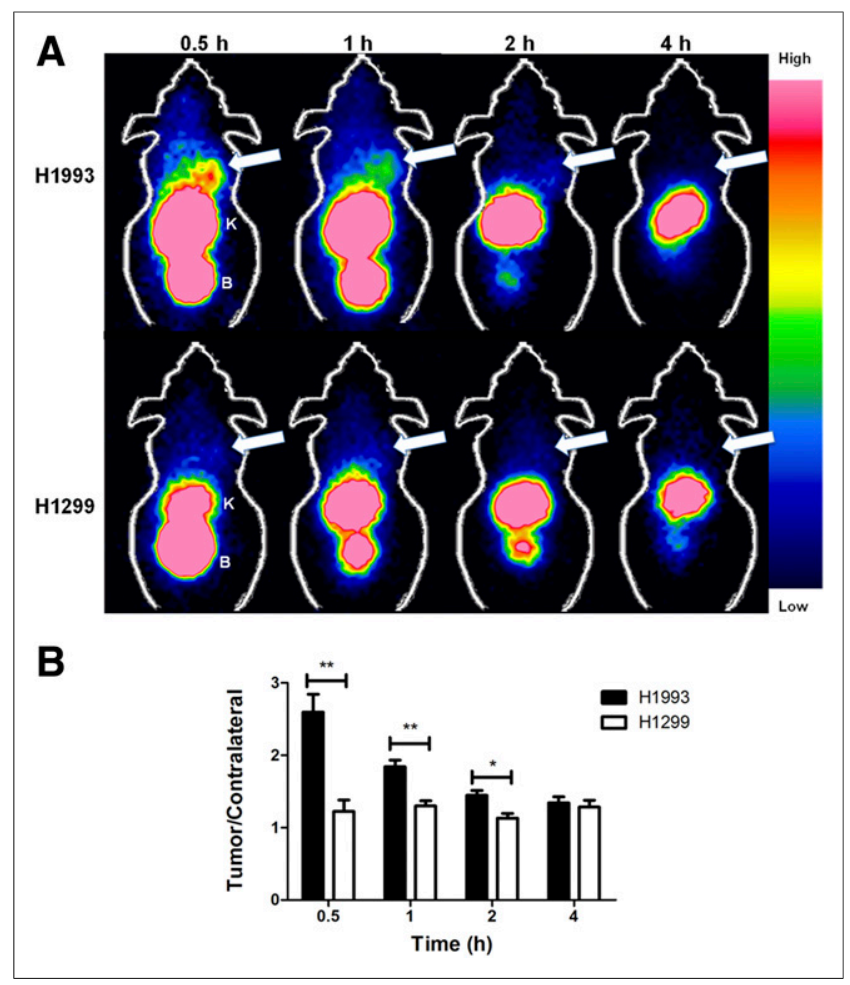

FIGURE 3. (A) Representative coronal SPECT images of H1993 and $\mathrm{H} 1299$ xenografts $0-4 \mathrm{~h}$ after injection of $99 \mathrm{mTc}-\mathrm{HYNIC}-\mathrm{cMBP}$. Arrows $=$ tumor; $\mathrm{B}=$ bladder; $\mathrm{K}=$ kidney. (B) Quantitative analysis of images through counts in region of interest. ${ }^{\star} P<0.05 .{ }^{\star \star} P<0.01$.

was internalized in c-Met-positive H1993 cells. The tracer exhibited a trend toward an increasing internalization rate, with a maximum of $10.21 \% \pm 0.46 \%$ cell-associated activity at $120 \mathrm{~min}$ followed by a plateau.

\section{In Vitro and In Vivo Stability Assays}

According to radio-HPLC analyses, the retention time of ${ }^{99 \mathrm{~m}} \mathrm{Tc}$ HYNIC-cMBP was $6.5 \mathrm{~min}$, and more than $98 \%$ of the tracer remained intact during a $0-4 \mathrm{~h}$ incubation in mouse serum and PBS (Supplemental Figs. 3A and 3B). The results showed that ${ }^{99 m}$ Tc-HYNIC-cMBP was highly stable in vitro. In vivo stability measured by radio-HPLC under identical conditions is shown in Figure 2. At $1 \mathrm{~h}$, intact tracer in plasma and tumor was $98 \%$ and $96 \%$, respectively, and intact tracer in liver and urine was $40 \%$ and $54 \%$, respectively. These results suggest excellent in vivo stability for $99 \mathrm{~m}$ Tc-HYNIC-cMBP, with expected degradation through the hepatobiliary and urinary systems.

\section{In Vivo SPECT Imaging and Blocking Assays}

99mTc-HYNIC-cMBP provided effective SPECT imaging of cMet-positive H1993 tumors (Fig. 3A, top), with H1299 tumors serving as a negative control (Fig. 3A, bottom). Quantitative analyses of the region of interest expressed as $\mathrm{T} / \mathrm{C}$ ratios are shown in Figure 3B.

H1993 xenografts were clearly visualized by SPECT imaging at $0.5 \mathrm{~h}$, with the highest $\mathrm{T} / \mathrm{C}$ ratio being $2.60 \pm 0.35$, whereas H1299 xenografts were not detected (T/C ratio, $1.22 \pm 0.22)$. $\mathrm{H} 1993$ xenografts remained detectable at $1 \mathrm{~h}$, but the T/C ratio decreased to $1.90 \pm 0.13$. ${ }^{99 \mathrm{~m}} \mathrm{Tc}-\mathrm{HYNIC}$-cMBP cleared from tumors within 2-4 h, likely because the tracer lacked lipophilicity.
Thus, $0.5 \mathrm{~h}$ was the optimum imaging time for ${ }^{99 \mathrm{~m}} \mathrm{Tc}-\mathrm{HYNIC}$ cMBP in NSCLC. In H1299 xenografts, no obvious tumor activity was detected over time, with $\mathrm{T} / \mathrm{C}$ ratios ranging from $1.13 \pm 0.09$ to $1.29 \pm 0.10$, consistent with negligible c-Met expression. Activity was highest in the kidney and bladder, indicating that ${ }^{99 \mathrm{~m}} \mathrm{Tc}-$ HYNIC-cMBP is cleared primarily via the urinary system.

Representative SPECT images and quantitative analyses for blocking experiments are shown in Figures $4 \mathrm{~A}$ and $4 \mathrm{~B}$, respectively. After pretreatment with an excess of nonradiolabeled cMBP, H1993 xenografts were difficult to discern in images. Consistently, ${ }^{99 m}$ Tc-HYNIC-cMBP accumulation in pretreated $\mathrm{H} 1993$ tumors was significantly lower (T/C ratio, $1.29 \pm 0.11)$. Collectively, these results support that ${ }^{99 \mathrm{~m}} \mathrm{Tc}-\mathrm{HYNIC}-\mathrm{cMBP}$ specifically accumulates in c-Met-positive H1993 xenografts in vivo.

\section{Biodistribution and Pharmacokinetics}

To confirm the SPECT imaging results, the biodistribution of ${ }^{99 m}$ Tc-HYNIC-cMBP was assessed in mice bearing H1993 and H1299 xenografts. As shown in Supplemental Tables 1 and 2 and in Figure 5, the highest percentage injected dose (\%ID) in $\mathrm{H} 1993$ xenografts was at $0.5 \mathrm{~h}(4.74 \pm 1.43 \% \mathrm{ID} / \mathrm{g})$, then decreasing at $1 \mathrm{~h}(2.84 \pm 0.28 \% \mathrm{ID} / \mathrm{g})$ and further declining at 2 and $4 \mathrm{~h}(0.87 \pm 0.13$ and $0.75 \pm 0.14 \% \mathrm{ID} / \mathrm{g}$, respectively $)$. In contrast, uptake in $\mathrm{H} 1299$ xenografts was significantly lower at 0.5 and $1 \mathrm{~h}(1.00 \pm 0.37$ and $0.71 \pm 0.13 \% \mathrm{ID} / \mathrm{g}$, respectively). Uptake in nontarget tissues was similar in H1993 and H1299 xenograft-bearing mice. The signal was highest in kidney at $0.5 \mathrm{~h}$ $(252.66 \pm 44.37 \% \mathrm{ID} / \mathrm{g}$ in $\mathrm{H} 1299$ and $247.55 \pm 40.52 \% \mathrm{ID} / \mathrm{g}$ in H1993) and then decreased over time, further suggesting that ${ }^{99 m}$ Tc-HYNIC-cMBP is rapidly cleared through the urinary system. Blocking assays demonstrated that uptake was significantly reduced in $\mathrm{H} 1993$ xenografts $(1.02 \pm 0.43 \% \mathrm{ID} / \mathrm{g})$ with an excess of nonradiolabeled cMBP. Probe uptake for different organs did not differ $(P>0.05)$ between the H1993 and the H1993-block groups, excluding the tumors $(P<0.05)$.

Protein-to-plasma and supernatant-to-plasma activity, the proteinto-plasma binding ratio of ${ }^{99 \mathrm{~m}} \mathrm{Tc}-\mathrm{HYNIC}-\mathrm{cMBP}$ to total plasma activity, was determined to be $0.10 \pm 0.02$ at $30 \mathrm{~min}$. The timelogarithmic value of the plasma activity curve was plotted (Supplemental Fig. 4), and the elimination rate constant was calculated to be $0.02 \pm 0.001 / \mathrm{min}$. The elimination half-life was $32.80 \pm 4.21 \mathrm{~min}$.

\section{Autoradiography}

The radioactivity exposure, hematoxylin and eosin staining, and immunofluorescence staining of consecutive tumor sections are presented in Figure 6. The results revealed preferential accumulation

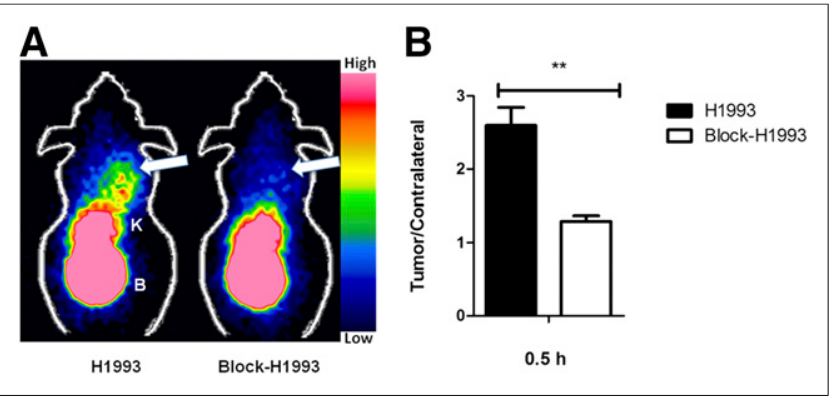

FIGURE 4. (A) Representative coronal SPECT images for H1993 and block-H1993 xenografts at $0.5 \mathrm{~h}$. Arrows $=$ tumor; $\mathrm{B}=$ bladder; $\mathrm{K}=$ kidney. (B) Quantitative analysis of images through counts in region of interest. ${ }^{*} P<0.01$. 


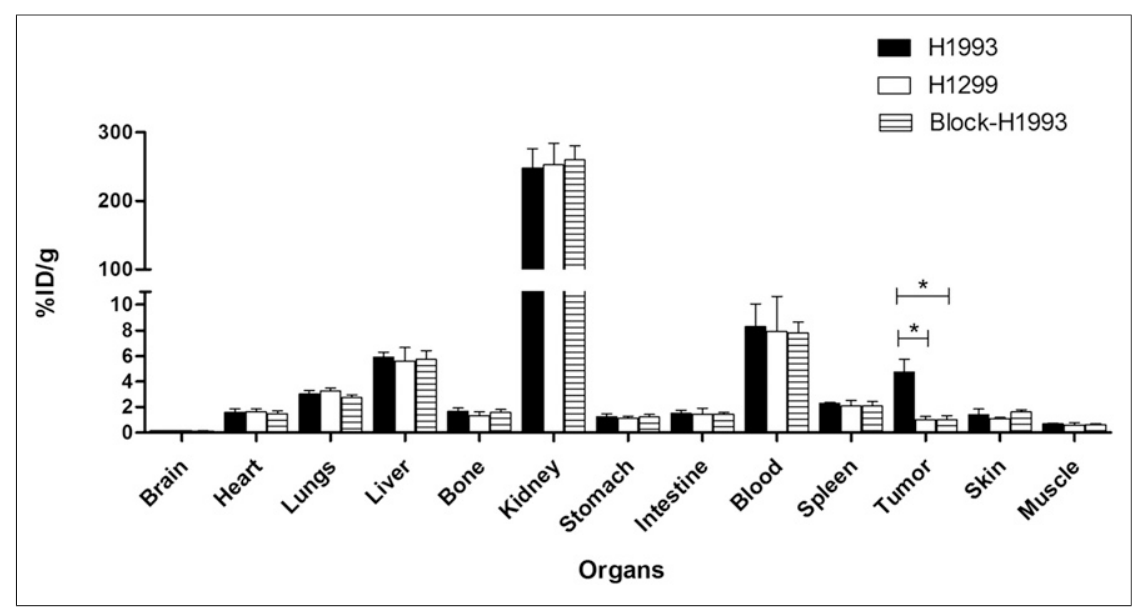

FIGURE 5. Biodistribution of 99mTc-HYNIC-cMBP in $\mathrm{H} 1993, \mathrm{H} 1299$, and block-H1993 groups at $0.5 \mathrm{~h}$ after injection. ${ }^{*} P<0.05$.

of ${ }^{99 m}$ Tc-HYNIC-cMBP in H1993 tumors, whereas no accumulation other than background signal was found in H1299 tumors, demonstrating that ${ }^{99 \mathrm{~m}} \mathrm{Tc}-\mathrm{HYNIC}-\mathrm{cMBP}$ specifically binds to c-Met-positive tumors. Importantly, the intratumoral distribution of ${ }^{99 \mathrm{~m} T c-H Y N I C-}$ cMBP in H1993 tumor sections reflected the heterogeneity of NSCLC.

\section{In Vitro Assays}

Confirmed by Western blots, high c-Met expression was detected in H1993 cells and xenografts but not in H1299 cells and xenografts (Supplemental Figs. 5A and 5B). Similarly, a significantly more intense fluorescence signal was observed by

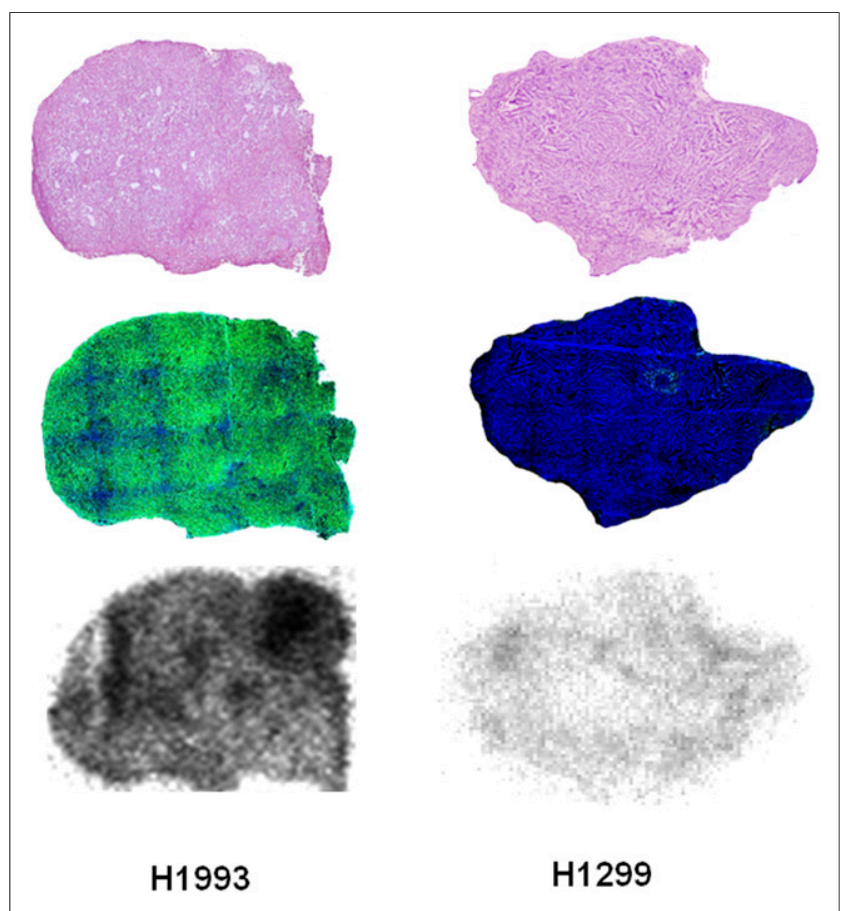

FIGURE 6. Comparison of hematoxylin and eosin staining (top), immunofluorescence staining (middle), and autoradiography images (bottom) of $\mathrm{H} 1993$ and $\mathrm{H} 1299$ tumor sections at $0.5 \mathrm{~h}$ after injection of ${ }^{99 \mathrm{~m} T \mathrm{C}-}$ HYNIC-cMBP. Green fluorescence indicates high expression of c-Met. immunostaining in $\mathrm{H} 1993$ cells, whereas signal was negligible in H1299 cells (Supplemental Fig. 5C).

\section{DISCUSSION}

Over the decades, c-Met has emerged as a promising therapeutic tumor target (28). Various molecular imaging strategies evaluating c-Met expression in cancer have been reported (29) - mainly strategies involving antibody-based or peptide-based imaging agents. Although antibody-based c-Met-targeted imaging has been widely researched, inherent limitations such as large size, weak tissue penetration, prolonged clearance, and potential immunogenicity have diminished its utility (30).

Low-molecular-weight peptides offer many advantages in molecular imaging, including more favorable pharmacokinetics and tissue penetration, a lower risk of immunogenicity and toxicity, and flexibility in chemical modification $(16,31)$. To date, the only c-Met-targeted probe in clinical trials is GE-137, a fluorescently labeled c-Metspecific peptide that has been used successfully to detect malignant polyps in patients at high risk of colon cancer (17). However, optical imaging is applied mainly to detect superficial tissue externally or in endoscopic procedures, and nuclear imaging is more useful in whole-body imaging.

In this study, the feasibility of using ${ }^{99 \mathrm{~m}} \mathrm{Tc}-\mathrm{HYNIC}-\mathrm{cMBP}$ to detect NSCLC by SPECT imaging was investigated. As a way to mediate resistance to epidermal growth factor receptor-targeted therapy in NSCLC $(7,8)$, c-Met imaging might provide a new strategy for NSCLC diagnosis and treatment.

With a molecular weight of only $1.6 \mathrm{kDa}$, cMBP is significantly smaller than monoclonal antibodies $(\sim 150 \mathrm{kDa})$ or derivatives $(19,20)$. Moreover, as compared with other positron radionuclidelabeled tracers, radiolabeling with ${ }^{99 \mathrm{~m}} \mathrm{Tc}$ was simple, with high yield and low cost. Our results indicate that ${ }^{99 m} \mathrm{Tc}-\mathrm{HYNIC}-\mathrm{cMBP}$ is a promising radiotracer for targeting c-Met in vivo and in vitro. When compared with other previously reported tracers targeting cMet (e.g., $18.1 \pm 4.5 \% \mathrm{ID} / \mathrm{g}$ for ${ }^{89} \mathrm{Zr}$-DN30 in GTL-16 gastric cancer and $3.4 \pm 0.3 \% \mathrm{ID} / \mathrm{g}$ for ${ }^{89} \mathrm{Zr}-\mathrm{DFO}-\mathrm{H} 2$ cys-diabody in Hcc827-GR NSCLC when there is optimal image contrast) $(14,15)$, the smaller ${ }^{99 m}$ Tc-HYNIC-cMBP showed moderate uptake $(4.74 \pm 1.43 \% \mathrm{ID} / \mathrm{g})$. However, H1993 tumors were clearly visualized in SPECT images at as early as $0.5 \mathrm{~h}$. Additionally, ${ }^{99 \mathrm{~m}} \mathrm{Tc}-$ HYNIC-cMBP cleared rapidly via the renal system, as is consistent with water-soluble low-molecular-weight probes, albeit unattractive for imaging tumors of the urinary system $(32,33)$. Nevertheless, rapid clearance is a desirable property for diagnostic tracers, as it reduces tissue exposure to radiation, background noise, and long delays between contrast treatment and image readout for receptortargeted imaging. Although it is difficult to directly compare c-Mettargeted tracers because of intrinsic differences in tumor models, peptide-based tracers tend to produce high-contrast images at earlier times than antibody-based tracers, as there is better tissue penetration and more rapid elimination.

Despite these advantages, ${ }^{99 \mathrm{~m} T c-H Y N I C-c M B P}$ had limitations, such as a short retention time in tumors and a low resolution of anatomic structures in images. Furthermore, the optimal imaging 
time of ${ }^{99 m}$ Tc-HYNIC-cMBP, 30 min, may not allow sufficient time for preparation, and it may be preferable to extend this imaging time to approximately $1 \mathrm{~h}$, as is the case for ${ }^{18} \mathrm{~F}-\mathrm{FDG}(34)$. Thus, in future studies, the efficacy of ${ }^{99 \mathrm{~m}} \mathrm{Tc}-\mathrm{HYNIC}-\mathrm{cMBP}$ might be improved by introducing an amino octanoic acid to increase peptide lipophilicity (35) or by creating dimers, such as dimeric arginine-glycine-aspartic acid peptide, to increase binding affinity $(36,37)$. Small-animal SPECT imaging may appropriately provide not only anatomic information with higher resolution but also dynamic imaging with better quantitative analysis and pharmacokinetics modeling.

\section{CONCLUSION}

This study provided proof of the concept of using a novel peptide-based tracer targeting c-Met for SPECT imaging. ${ }^{99 \mathrm{~m}} \mathrm{Tc}-$ HYNIC-cMBP specifically bound to c-Met in vitro and in vivo. Although further modification and optimization are warranted, cMBP-based radiotracers may be translated into the clinic for the selection and monitoring of NSCLC patients to receive c-Metresponsive therapy.

\section{DISCLOSURE}

This work was supported partly by the National Natural Science Foundation of China (81471724, 81627901, 31210103913, 81101088, and 81130028), the National Basic Research Program of China (2015CB931800), the Heilongjiang Province Foundation for Returned Overseas Chinese Scholars, and the Key Laboratory of Molecular Imaging Foundation (College of Heilongjiang Province). No other potential conflict of interest relevant to this article was reported.

\section{ACKNOWLEDGMENTS}

We thank Po Yang, Yingxun Zhang, Yali Cui, Yongyi Wu, Feng Chen, and Tengchuang Ma for technical support.

\section{REFERENCES}

1. Cooper CS, Park M, Blair DG, et al. Molecular cloning of a new transforming gene from a chemically transformed human cell line. Nature. 1984;311:29-33.

2. Trusolino L, Bertotti A, Comoglio PM. MET signalling: principles and functions in development, organ regeneration and cancer. Nat Rev Mol Cell Biol. 2010;11:834-848.

3. Gherardi E, Birchmeier W, Birchmeier C, Vande Woude G. Targeting MET in cancer: rationale and progress. Nat Rev Cancer. 2012;12:89-103.

4. Birchmeier C, Birchmeier W, Gherardi E, Vande Woude GF. Met, metastasis, motility and more. Nat Rev Mol Cell Biol. 2003;4:915-925.

5. Herbst RS, Heymach JV, Lippman SM. Lung cancer. N Engl J Med. 2008;359: 1367-1380.

6. Wender R, Fontham ET, Barrera E Jr, et al. American Cancer Society lung cancer screening guidelines. CA Cancer J Clin. 2013;63:107-117.

7. Robinson KW, Sandler AB. The role of MET receptor tyrosine kinase in nonsmall cell lung cancer and clinical development of targeted anti-MET agents. Oncologist. 2013;18:115-122.

8. Engelman JA, Zejnullahu K, Mitsudomi T, et al. MET amplification leads to gefitinib resistance in lung cancer by activating ERBB3 signaling. Science. 2007; 316:1039-1043.

9. Zucali PA, Ruiz MG, Giovannetti E, et al. Role of cMET expression in nonsmall-cell lung cancer patients treated with EGFR tyrosine kinase inhibitors. Ann Oncol. 2008;19:1605-1612.

10. Liu X, Newton RC, Scherle PA. Developing c-MET pathway inhibitors for cancer therapy: progress and challenges. Trends Mol Med. 2010;16:37-45.

11. Spigel DR, Edelman MJ, O'Byrne K, et al. Results from the phase III randomized trial of onartuzumab plus erlotinib versus erlotinib in previously treated stage IIIB or IV non-small-cell lung cancer: METlung. J Clin Oncol. 2017;35:412-420.
12. de Koning HJ, Meza R, Plevritis SK, et al. Benefits and harms of computed tomography lung cancer screening strategies: a comparative modeling study for the U.S. Preventive Services Task Force. Ann Intern Med. 2014;160:311-320.

13. Mendiratta-Lala M, Sheiman R, Brook OR, Gourtsoyianni S, Mahadevan A, Siewert B. CT-guided core biopsy and percutaneous fiducial seed placement in the lung: can these procedures be combined without an increase in complication rate or decrease in technical success? Eur J Radiol. 2014;83:720-725.

14. Perk LR, Stigter-van Walsum M, Visser GW, et al. Quantitative PET imaging of Met-expressing human cancer xenografts with ${ }^{89} \mathrm{Zr}$-labelled monoclonal antibody DN30. Eur J Nucl Med Mol Imaging. 2008;35:1857-1867.

15. Li K, Tavare R, Zettlitz KA, et al. Anti-MET immunoPET for non-small cell lung cancer using novel fully human antibody fragments. Mol Cancer Ther. 2014; 13:2607-2617.

16. Lee S, Xie J, Chen X. Peptide-based probes for targeted molecular imaging. Biochemistry. 2010;49:1364-1376.

17. Burggraaf J, Kamerling IM, Gordon PB, et al. Detection of colorectal polyps in humans using an intravenously administered fluorescent peptide targeted against c-Met. Nat Med. 2015;21:955-961.

18. Arulappu A, Battle M, Eisenblaetter M, et al. c-Met PET imaging detects early-stage locoregional recurrence of basal-like breast cancer. J Nucl Med. 2016;57:765-770.

19. Kim K, Hur Y, Ryu EK, et al. A neutralizable epitope is induced on HGF upon its interaction with its receptor cMet. Biochem Biophys Res Commun. 2007;354: $115-121$.

20. Kim EM, Park EH, Cheong SJ, et al. In vivo imaging of mesenchymal-epithelial transition factor (c-Met) expression using an optical imaging system. Bioconjug Chem. 2009;20:1299-1306.

21. Yan Y, Xiao ZY, Song Y, et al. ${ }^{99} \mathrm{mTc}-\mathrm{HYNIC}-\mathrm{MPG}$ : a novel SPECT probe for targeting mutated EGFR. Bioorg Med Chem Lett. 2015;25:1647-1652.

22. Song Y, Xiao Z, Wang K, et al. Development and evaluation of ${ }^{18} \mathrm{~F}$-IRS for molecular imaging mutant EGF receptors in NSCLC. Sci Rep. 2017;7:3121.

23. Khodadust F, Ahmadpour S, Aligholikhamseh N, Abedi SM, Hosseinimehr SJ. An improved ${ }^{99 m}$ Tc-HYNIC-(Ser)3-LTVSPWY peptide with EDDA/tricine as co-ligands for targeting and imaging of HER2 overexpression tumor. Eur $J$ Med Chem. 2018;144:767-773.

24. Altai M, Perols A, Karlstrom AE, et al. Preclinical evaluation of anti-HER2 affibody molecules site-specifically labeled with ${ }^{111}$ In using a maleimido derivative of NODAGA. Nucl Med Biol. 2012;39:518-529.

25. Jiang L, Kimura RH, Miao Z, et al. Evaluation of a ${ }^{64} \mathrm{Cu}$-labeled cystine-knot peptide based on agouti-related protein for PET of tumors expressing alphavbeta3 integrin. $J$ Nucl Med. 2010;51:251-258.

26. Autio A, Henttinen T, Sipila HJ, Jalkanen S, Roivainen A. Mini-PEG spacering of VAP-1-targeting ${ }^{68} \mathrm{Ga}$-DOTAVAP-P1 peptide improves PET imaging of inflammation. EJNMMI Res. 2011;1:10.

27. Dong C, Liu Z, Wang F. Radioligand saturation binding for quantitative analysis of ligand-receptor interactions. Biophys Rep. 2015;1:148-155.

28. Blumenschein GR Jr, Mills GB, Gonzalez-Angulo AM. Targeting the hepatocyte growth factor-cMET axis in cancer therapy. J Clin Oncol. 2012;30:3287-3296.

29. Pool M, van Dam GM, de Vries EG. Emerging opportunities for c-MET visualization in the clinic. $J$ Nucl Med. 2016;57:663-664.

30. Wu AM, Olafsen T. Antibodies for molecular imaging of cancer. Cancer J. 2008;14:191-197.

31. Chen K, Chen X. Design and development of molecular imaging probes. Curr Top Med Chem. 2010;10:1227-1236.

32. Katsila T, Siskos AP, Tamvakopoulos C. Peptide and protein drugs: the study of their metabolism and catabolism by mass spectrometry. Mass Spectrom Rev. 2012;31:110-133.

33. Ebenhan T, Schoeman I, Rossouw DD, et al. Evaluation of a flexible NOTA-RGD kit solution using gallium-68 from different ${ }^{68} \mathrm{Ge} /{ }^{68} \mathrm{Ga}$-generators: pharmacokinetics and biodistribution in nonhuman primates and demonstration of solitary pulmonary nodule imaging in humans. Mol Imaging Biol. 2017;19:469-482.

34. Lowe VJ, DeLong DM, Hoffman JM, Coleman RE. Optimum scanning protocol for FDG-PET evaluation of pulmonary malignancy. J Nucl Med. 1995;36:883887.

35. Sun Y, Ma X, Zhang Z, et al. Preclinical study on GRPR-targeted ${ }^{68}$ Ga-probes for PET imaging of prostate cancer. Bioconjug Chem. 2016;27:1857-1864.

36. Janssen M, Oyen WJ, Massuger LF, et al. Comparison of a monomeric and dimeric radiolabeled RGD-peptide for tumor targeting. Cancer Biother Radiopharm. 2002;17:641-646.

37. Thumshirn G, Hersel U, Goodman SL, Kessler H. Multimeric cyclic RGD peptides as potential tools for tumor targeting: solid-phase peptide synthesis and chemoselective oxime ligation. Chemistry. 2003;9:2717-2725. 